\title{
O PODER DA COROA E O PODER DO ANEL: RESSONÂNCIAS SHAKESPEARIANAS NA LITERATURA DE FANTASIA DE J. R. R. TOLKIEN
}

Flávia Rodrigues Monteiro

Mestre em Literaturas de Expressão Inglesa do Programa de Pós-Graduação em Estudos Literários / UFMG

\begin{abstract}
RESUMO
Os ecos shakespearianos aparecem na literatura de fantasia de J. R. R. Tolkien apontando vários aspectos de conflito humano. Esta pesquisa analisa tais ecos com foco no âmbito das relações de poder herdadas das peças Hamlet, Macbeth e A tempestade, demonstrando como o poder, seja seu símbolo uma coroa ou um anel, pode influenciar a natureza humana.
\end{abstract}

\section{PALAVRAS-CHAVE}

Shakespeare, Tolkien, herança cultural, poder

\section{INTRODUÇÃO}

São inegáveis as ressonâncias shakespearianas através dos séculos nos mais diversos campos das artes e, em especial, no século 20, com a popularização de novas mídias, como o cinema. Shakespeare foi adaptado e readaptado, assim como os discursos políticos e sociais contidos em suas peças, criando uma grande rede de compartilhamento de temas comuns à cultura humana. Seus ecos estenderam-se não somente por outras mídias, mas também dentro dos mais diversos segmentos da própria literatura. Devido ao seu caráter predominantemente épico, abordando personagens e situações, tais como reis travando guerras para defender seus domínios, a literatura de fantasia reproduz nos séculos 20 e 21 temas já abordados nas produções shakespearianas. Porém, Shakespeare não chega até a literatura de fantasia simplesmente como uma coincidência ou simples escolha intertextual; ele traz consigo um discurso no qual se percebe vários aspectos dos conflitos humanos: individuais, sociais e políticos. Portanto, o presente trabalho pretende apontar e analisar ecos shakespearianos na literatura de fantasia, mais especificamente na obra de J. R. R. Tolkien, O senhor dos anéis. O 
foco da análise abrangerá o caráter conflitual da natureza humana compartilhado por ambas as obras, especialmente no campo das relações de poder.

O trabalho começará por uma delimitação dos contextos dos autores e em seguida focará nos ecos das peças Hamlet, Macbeth e A tempestade na obra de Tolkien no campo das relações de/com o poder. Por fim, apresentarei uma breve conclusão, discorrendo em torno do tema abordado na pesquisa, o poder, além de tocar em um tema recorrente nos estudos sobre Shakespeare, a "permanência” dos escritos do Bardo através de culturas e tempos. Com isso, questões relacionadas ao uso da teoria para uma melhor compreensão da produção literária shakespeariana e sua rica herança para leitores contemporâneos também terão seu espaço.

\section{CONTEXTOS}

A delimitação dos contextos dos autores se faz necessária ao considerarmos, como Ezra Pound em seu livro $A B C$ da Literatura, ${ }^{1}$ que os artistas são como antenas de suas épocas. Eles captam os acontecimentos de suas épocas e os refletem em suas obras. Assim, ao mostrar as similaridades das escritas, bem como as similaridades contextuais, abrimos espaço para a exploração de campos da cultura humana, considerados como “essenciais”. "Essencial” é empregado como um termo que designa os aspectos comuns em variadas culturas e variados tempos, possibilitando e instigando a discussão a respeito de uma natureza humana em contraste com uma cultura humana.

Ao apontar compartilhamentos contextuais e literários entre os dois autores, faz-se notar que pelo menos alguns aspectos humanos manifestados culturalmente possuem um caráter coincidente. Porém, devemos levar em conta que os autores, embora separados historicamente e/ou até socialmente, habitam o mesmo ambiente cultural: a Grã-Bretanha. Desde já, justifico minha posição por trabalhar com termos como "ecos” e "ressonâncias”, e não com termos que instiguem generalizações. O termo "essencial”, assim como o termo "universal”, possui caráter amplo, o que pode levar a enganos e interpretações errôneas. Portanto, prefiro a expressão "recortes de ressonâncias", pois não pretendo explorar a totalidade contextual e textual dos autores, o que podemos considerar muito pretensioso devido aos infinitos fatores a serem analisados; ao invés disso, oferecerei um breve olhar sobre pequenos fragmentos desse grande mosaico histórico e literário.

\section{CONTEXTO HISTÓRICO SHAKESPEARIANO}

\footnotetext{
${ }^{1}$ POUND. ABC da Literatura, p. 71.
} 
Antes de contemplar um breve olhar sobre o contexto histórico shakespeariano, é necessário salientar que não serão exploradas aqui as especulações acerca da verdadeira identidade do Bardo, visando manter o foco da análise proposta.

William Shakespeare viveu de 1564 até 1616, período que viu os reinados da Rainha Elizabeth I e de seu sucessor, o rei James I. A Rainha Elizabeth governou de 1558 até 1603 e seu reinado marcou uma época de prosperidade para a Inglaterra, tanto no âmbito interno quanto na expansão de seus domínios externos. Internamente, a Inglaterra passava por um período de transição carregado de contradições:

Com o carisma político de Elizabeth, seu reinado caracterizou-se como um período de transformações materiais, enriquecimento e desenvolvimento de potencialidades. Houve um grande fortalecimento da monarquia e favorecimento da burguesia. Seria o fim da Idade Média, dos barões poderosos, das famílias rivais e em luta. Entretanto também se apresentavam contradições. Embora as discussões versassem sobre temas essenciais à vida humana, as circunstâncias sociais apresentavam uma realidade que estimulava o ceticismo e a descrença. Por outro lado, a investigação da conduta humana e a busca de explicação do universo causavam crendices e superstição, traços ditos medievais que resistiam numa época em que se viviam a racionalidade científica e suas descobertas. ${ }^{2}$

A Rainha Elizabeth soube lidar com disparidades políticas e religiosas que chegaram ao seu reinado como uma herança do reinado de seu pai, o rei Henrique VIII. Suas habilidades como governante fizeram da Rainha Elizabeth I um ícone de popularidade, e seu reinado ficou conhecido como Era Dourada; consequentemente, o poder da monarquia se consolidou ainda mais. Valores renascentistas ecoaram na Inglaterra, assim como em outras partes da Europa, apesar de o seu verdadeiro berço ter sido a região da Itália. A princípio, o humanismo de Elizabeth agradava por sua tolerância à resistência inglesa da época de romper com certas heranças do passado, a Idade Média, como a existência de crendices e superstições relacionadas a indagações metafísicas. Além disso, o desenvolvimento econômico e da burguesia possibilitou o financiamento de aventuras imperialistas e de grandes navegações, resultando numa expansão do império britânico através de tentativas de colonizar novas terras.

Por outro lado, o governo de Elizabeth se tornou cada vez mais tirânico e a rainha punia severamente o que considerava ser uma ameaça à ordem estabelecida por seu governo, tendo como exemplos as execuções de sua irmã Mary Stuart (uma seguidora declarada da fé católica) e do conde de Essex (um nobre, parente de Elizabeth, que planejou uma revolta

\footnotetext{
${ }^{2}$ VASCONCELOS. Ligações e afiliações: Shakespeare e o contexto elisabetano-jacobino, p. 119.
} 
contra o governo e teve seus planos descobertos). Além disso, os benefícios do governo elisabetano se concentravam no eixo burguesia-nobreza e possíveis revoltas de camadas mais desfavorecidas da população deveriam ser contidas a qualquer custo para que a ordem estabelecida não fosse abalada.

Em 1603, teve inicio o reinado jacobino, quando o rei James I subiu ao trono e governou até 1625. O governo de James I foi uma continuação do governo predecessor, com uma política absolutista que enfrentava com rigidez a insatisfação dos revoltosos. Contudo, o novo governo também deu grande valor às artes e à erudição, sendo que o próprio rei se aventurou no campo literário. Portanto, o contexto político e social shakespeariano fornecia os elementos para uma construção eficiente do entretenimento da época, o teatro, da mesma forma como uma parte considerável do cinema contemporâneo. Segundo Ian kott:

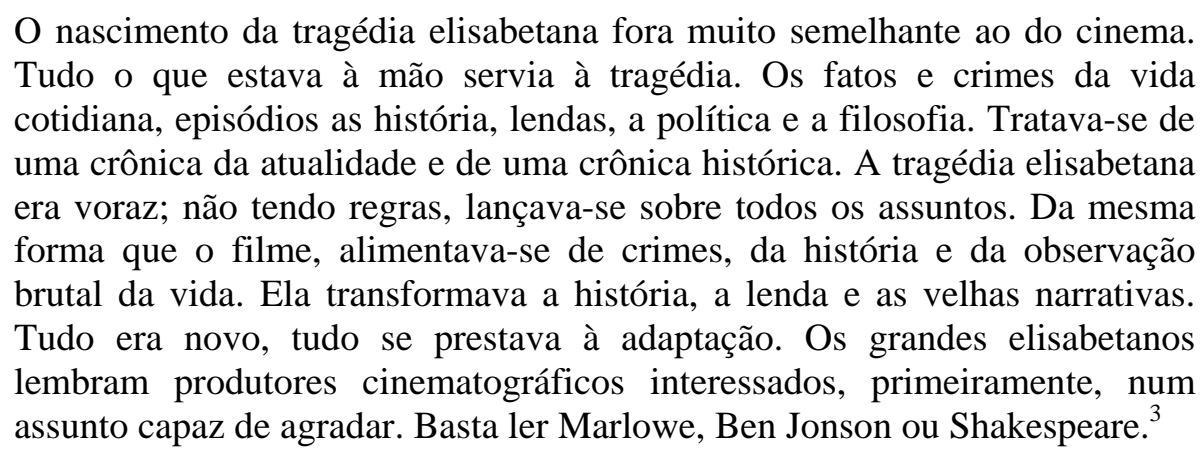

Shakespeare, como uma antena de sua época, captou o caráter contraditório de seu tempo e o refletiu em suas obras. O dramaturgo fazia parte de uma camada da burguesia que vivia do patrocínio dos nobres interessados em sua arte. Da mesma forma que um cineasta procura agradar ao público, os estúdios que financiam sua obra e também a sua arte, o Bardo, por um lado, tinha que agradar o "poder” que o patrocinava e, por outro, ele não podia omitir os acontecimentos que chegavam ao seu conhecimento. Daí surge a complexidade atribuída às suas obras. O domínio humano não pode ser considerado como algo simplista em nenhuma de suas eras; seu caráter multifacetado e suas diferentes manifestações culturais podem ser uma justificativa para a atribuída natureza universal do Bardo. Mas qual a razão de Shakespeare ser tão reverenciado e não um "filme pipoca” hollywoodiano? A resposta pode estar na maestria e no talento individual de Shakespeare ao construir com a forma e os elementos mais propícios cada uma de suas obras. De acordo com Kott, "Shakespeare é semelhante ao mundo ou à vida. Cada época encontra nele o que busca ou o que quer ler”.

\footnotetext{
${ }^{3}$ KOTT. Shakespeare nosso contemporâneo, p. 104.

${ }^{4}$ KOTT. Shakespeare nosso contemporâneo, p. 27.
} 


\section{CONTEXTO HISTÓRICO DE TOLKIEN}

John Ronald Reuel Tolkien nasceu em 1892 na África do Sul, onde seu pai trabalhava como bancário. Filho de pais britânicos, Tolkien foi morar na Inglaterra aos 3 anos de idade com sua mãe e lá permaneceu após a morte de seu pai. Acadêmico da área de Letras, excombatente de guerra, um apaixonado por linguística (criou para seus livros cerca de 14 idiomas diferentes) e escritor, Tolkien faleceu em 1973.

J. R. R. Tolkien, como é mais conhecido, nasceu durante o governo da rainha Vitória, que se estendeu de 1837 até 1901. O período, que ficou conhecido historicamente como Era Vitoriana, foi marcado pela expansão e consolidação dos domínios do Império Britânico. Durante esse período, o governo britânico enfrentou diversas revoltas nas áreas de sua dominância, especialmente no Novo Mundo. Contudo, a Inglaterra não sofreu grandes abalos por tais conflitos e continuou a ser um império próspero e poderoso. Em 1901, após a morte de sua mãe, Edward VII subiu ao trono e teve um breve reinado até 1910, quando morreu e foi substituído por seu filho, George V. Durante o reinado de George V, o Império Britânico foi um dos protagonistas da Primeira Guerra Mundial.

Um ano após se graduar em Literatura de Língua Inglesa, Tolkien foi convocado para lutar na guerra em 1916 e só retornou à Inglaterra em 1918, depois de perder a maioria de seus amigos nos campos de batalha. No prefácio de seu livro O senhor dos anéis, Tolkien escreveu:

Na verdade, é preciso estar pessoalmente sob a sombra da guerra para sentir totalmente sua opressão; mas, conforme os anos passam, parece que fica cada vez mais esquecido o fato de que ser apanhado na juventude por 1914 não foi uma experiência menos terrível do que ficar envolvido com 1939 e os anos seguintes. Em 1918, todos os meus amigos íntimos, com a exceção de um, estavam mortos. ${ }^{5}$

Em 1936, após a abdicação de Edward VIII do seu direito ao trono, seu irmão, George VI, começa seu reinado e, assim como no reinado de George V, o Império Britânico enfrentou uma nova grande guerra, a Segunda Guerra Mundial. Desta vez, Tolkien não estava diretamente envolvido nos campos de batalha, mas sentia a sombra da guerra por ter um filho, Christopher, na mesma situação em que esteve um dia.

Ao escrever para seu filho Christopher, que servia na Royal Air Force em meio à Segunda Guerra Mundial, ele deu uma indicação clara de como sua própria experiência de guerra tinha influenciado sua arte. "Eu sinto dentre

\footnotetext{
${ }^{5}$ TOLKIEN. O senhor dos anéis, p. XVI.
} 
todas as tuas dores (algumas meramente físicas) o desejo de expressar teu sentimento sobre o bem, o mal, o justo e o sórdido de alguma forma: ao racionalizá-lo e evitar que ele simplesmente supure," ele disse. "No meu caso, ele gerou Margot e a História dos Gnomos.” A mitologia que foi por fim publicada como $O$ Silmarillion, retratando uma época em que Sauron de O Senhor dos Anéis era um simples servo do anjo caído Morgoth, surgiu do encontro entre um gênio imaginativo e a guerra que inaugurou a era moderna. ${ }^{6}$

Após o fim da guerra em 1945, a Europa, como palco principal do conflito, ficou destruída não somente no campo físico, mas também em outros campos, incluindo o econômico. O Império Britânico perdeu definitivamente diversos de seus domínios, como a Irlanda e a Índia. Duas novas potências mundiais com ideologias opostas sugiram, os Estados Unidos e a União Soviética, colocando o mundo sob a sombra da Guerra Fria. O rei George VI morreu em 1953 e sua filha, Elizabeth II, assumiu a coroa que sustenta até os dias atuais, tendo enfrentado crises políticas e econômicas.

Várias mudanças resultantes do crescimento industrial inglês incomodavam Tolkien profundamente. Avesso à tecnologia, o escritor preferia um modo de vida mais simples e cultivava uma nostalgia pelos dias que viveu no interior do país. Assim, Tolkien se considerava como um Hobbit, adepto dos prazeres simples da vida. Contudo, apesar de não levar uma vida com luxos, ele enfrentou dificuldades financeiras, por vezes tendo que acumular tarefas acadêmicas para garantir o sustento da família.

No aspecto religioso, Tolkien foi extremamente influenciado por sua mãe, que converteu-se do anglicanismo para o catolicismo, motivo pelo qual recebeu o desprezo de sua família. Ela morreu quando Tolkien tinha apenas 12 anos de idade. Mais tarde em sua vida, Tolkien demonstrou interesse em filosofia e seguia a fé Católica. Ele conheceu outro escritor católico de literatura de fantasia, C. S. Lewis, autor de As crônicas de Nárnia. Ambos os autores alegavam ter influências de suas crenças em suas escritas, embora tais influências não apareçam de forma explícita. Além das alegadas influências da mitologia cristã, Tolkien, como um acadêmico apaixonado por literatura e linguística, apresenta também em suas obras ressonâncias de grandes autores do passado, incluindo Shakespeare.

\footnotetext{
6 "Writing to his son Christopher, serving in the Royal Air Force in the midst of the Second World War, he gave a clear indication of how his own experience of war had influenced his art. 'I sense amongst all your pains (some merely physical) the desire to express your feeling about good, evil, fair, foul in some way: to rationalize it, and prevent it just festering,' he ultimately published as The Silmarillion, depicting a time when Sauron of The Lord of the Rings had been merely a servant of the fallen Angel Morgoth, arouse out of the encounter between an imaginative genius and the war that inaugurated the modern age" (GARTH. Tolkien and the Great War: the threshold of Middleearth, p. 38-9, tradução nossa).
} 


\section{RESSONÂNCIAS}

Apesar de não ser o precursor do gênero, Tolkien é considerado como o criador da literatura de fantasia moderna devido à repercussão de sua obra. Em $O$ senhor dos anéis, o escritor criou uma Terra de aspecto medieval habitada por diferentes tipos de seres como elfos, anões, hobbits e humanos. O livro foi primeiramente publicado em sua forma integral em 1954 e seu enredo gira em torno da jornada do hobbit Frodo para destruir o anel de poder criado por Lorde Sauron para controlar todos os povos da Terra-média. Sauron tem como servos criaturas como orcs e um mago maligno, Saruman. Frodo encontra em sua jornada o auxílio de humanos, Elfos, um anão, outros três hobbits e o mago Gandalf. A narrativa trata de temas como ambição, guerra, amizade, amor, renúncia, liberdade e companheirismo, dentre diversos outros pontos do domínio humano. Portanto, assim como Shakespeare, Tolkien não foi o primeiro a tratar de tais elementos do domínio humano, mas seu talento e dedicação transformaram sua obra em um ponto de referência para diversas outras que se seguiram.

A seguir, serão analisadas as ressonâncias shakespearianas na obra de Tolkien. Delimitei minha pesquisa a apenas três peças: Hamlet, Macbeth e A tempestade. Porém, considerando que as próprias peças de Shakespeare dialogam entre si, aspectos ressonantes presentes em outras peças do Bardo farão emergir os nomes de tais obras. Aspectos relativos ao poder serão o foco da análise de tais ressonâncias.

\section{RESSONÂNCIAS DE HAMLET EM O SENHOR DOS ANÉIS}

O senhor dos anéis é dividido em três livros: A sociedade do anel, As duas torres e $O$ retorno do rei. Em As duas torres, após se perder de Frodo, o humano Aragorn, o elfo Legolas e o mago Gandalf chegam ao reino de Rohan, berço de bravos cavaleiros. Seu rei, Théoden, encontra-se debilitado e sua vontade é controlada por seu sobrinho e conselheiro Gríma Língua de cobra. Como seu próprio nome indica, Língua de cobra envenena os ouvidos do rei Théoden com suas palavras, sendo um veículo para a magia negra de Saruman e deixando o rei impotente e sem voz própria, morto, como uma marionete nas mãos de Saruman. Percebemos aqui um eco do personagem shakespeariano Claudius, que realmente envenena o irmão para tomar o poder do trono da Dinamarca. Além disso, Claudius supostamente seduz a rainha para se tornar o rei. Na obra de Tolkien, as palavras de Gríma são descritas como um veneno nos ouvidos do rei, assim como o real veneno jogado por Claudius no ouvido do irmão enquanto este dormia. 
Através desse eco, podemos notar que o poder apresenta uma série de armadilhas: a atração exercida pelo poder pode se transformar em uma obsessão destrutiva; o poder pode ser manipulado, tornando-se apenas uma ilusão, uma ideologia falha na cabeça daquele que pensa ser poderoso; finalmente, o poder pode ser usurpado, transformando-se em algo efêmero para seus detentores. Cada um desses elementos (atração, ilusão e usurpação) funciona como peças da engrenagem cíclica do poder. Tais aspectos dizem respeito ao poder aqui analisado, o poder dos governantes, mas podem ser estendidos para qualquer esfera de poder do domínio humano. Dessa forma, a sina daqueles que ambicionam o poder se divide em duas partes: aqueles que conseguiram o poder se preocupam em mantê-lo/expandi-lo e aqueles que ainda não possuem o poder se preocupam em obtê-lo. Um exemplo desse ciclo observado por Shakespeare foi a repressão que Elizabeth I impôs aos seus opositores. Tolkien pôde vivenciar duas guerras mundiais e ver Hitler como um dos personagens principais de uma delas.

O sono em que foi morto o rei Hamlet pode ser visto de forma simbólica, como uma falta de alerta/atenção aos acontecimentos e possibilidades de usurpação de seu poder presentes ao redor do governante. Em A tempestade, Alonso, o rei de Nápoles, também quase é morto por seu irmão, enquanto dorme. Sebastian, o irmão de Alonso, tenta cometer o assassinato sob a influência das palavras de Antônio. Próspero "dormiu” ao se dedicar mais aos seus livros do que ao seu ducado e teve seu poder usurpado por seu irmão Antônio. O ciclo se prolifera.

A inércia do governante é a sua condenação. Detentores de poder devem estar sempre atentos às ameaças internas e externas. Em Hamlet, Claudius consegue a coroa e para mantêla, foca no combate à ameaça interna, o jovem Hamlet; contudo, ele se esquece da ameaça externa, Fortimbrás. Mesmo se o plano de Claudius para tirar o príncipe Hamlet de seu caminho funcionasse, ele seria derrotado pelas tropas de Fortimbrás.

Ao subestimar possíveis ameaças, detentores de poder colocam em risco sua posição. Alonso, Próspero e o rei Hamlet nunca imaginariam que a ameaça pudesse partir de seus entes próximos. Aí está a habilidade da dissimulação que pode render ao seu detentor o poder supremo. Em $O$ Silmarillion, livro que pode ser considerado como um prefácio de $O$ senhor dos anéis, Lorde Sauron “podia assumir muitas formas; e por muito tempo, se quisesse, ainda pôde aparentar nobreza e beleza, de modo a enganar a todos, à exceção dos extremamente cautelosos". 7 Lorde Sauron usou sua habilidade de dissimulação para criar a "ilusão de poder"

\footnotetext{
${ }^{7}$ TOLKIEN. O Silmarillion, p. 363.
} 
na cabeça daqueles que pretendia enganar. Enganou os elfos artífices de Ost-in-Edhil convencendo-os a fazer anéis de poder para governantes de elfos, anões e homens:

Ora, os elfos fizeram muitos anéis. Em segredo, porém, Sauron fez Um Anel para governar todos os outros; e o poder dos outros estava vinculado ao dele, de modo a submeter-se totalmente a ele e a durar somente enquanto ele durasse. E grande parte da força de vontade de Sauron foi transmitida àquele Um Anel. Pois o poder dos anéis élficos era enorme, e aquele que deveria governá-los deveria ser um objeto de potência extraordinária. E Sauron o forjou na Montanha de Fogo na Terra da Sombra. E, enquanto usava o Um Anel, ele conseguia perceber tudo o que era feito pelos anéis subalternos, e ler e controlar até mesmo os pensamentos daqueles que os usavam. ${ }^{8}$

O poder de Sauron durou enquanto conseguiu enganar muitos por um bom tempo. Dessa forma, pode-se dizer que o poder configura-se na habilidade de enganar muitos por muito tempo; e o poder absoluto reside na capacidade de enganar a todos o tempo todo. Ao usar o verbo "enganar”, refiro-me à capacidade de convencimento de que se deve seguir um poder nuclear em vez de dividi-lo de forma harmoniosa. Assim, a aceitação cega e sem questionamentos é a maior aliada daqueles que detêm ou visam o poder.

Ao centralizar o poder, Sauron ecoa uma figura shakespeariana que tem ligação direta com eventos históricos: Júlio César. Inspirada pelo evento histórico, a peça de Shakespeare explora em parte não somente a ascensão daquele que eliminou a democracia do Império Romano, mas também sua queda através de sua morte pelas mãos de senadores romanos, incluindo seu homem de confiança, Brutus. Gríma Língua de cobra ecoa Brutus, pois ambos sintetizam as ameaças internas e externas que o poder tem que enfrentar. Ambos se encontram na esfera interna e "de confiança” do poder, mas recebem influências de meios externos e se transformam em canais para deposição dos poderes que "servem”. Júlio César, que se encontra primeiramente no papel de usurpador, tem o seu poder usurpado. O mesmo acontece com Lorde Sauron, ao ter o Um Anel arrancado de seu dedo durante uma batalha. Tanto no caso de César quanto no de Sauron, podemos interpretar suas quedas como o resultado de seu orgulho e arrogância, pois se imaginavam intocáveis, indestrutíveis. Aqui entramos em um tema que será trabalhado na próxima seção: o sentimento de invencibilidade dos poderosos.

\section{RESSONÂNCIAS DE MACBETH EM O SENHOR DOS ANÉIS}

No livro As duas torres, os domínios da torre de Saruman em Isengard são destruídos

\footnotetext{
${ }^{8}$ TOLKIEN. O Silmarillion, p. 366-367.
} 
(de forma inimaginável) por um exército de árvores, os Ents. ${ }^{9}$ Aqui, vemos claramente um eco de Macbeth, referindo-se quando o rei Macbeth é surpreendido por árvores que caminham em direção ao seu castelo. No ato V, cena V, Macbeth diz ter quase se esquecido do que é sentir medo e depois relembra a profecia que dizia para não se preocupar até a floresta de Birnam vir em direção à Dunsinane. Da mesma forma que Macbeth não imaginaria que o exército de Malcom, do velho Siward e de MacDuff pudesse usar galhos de árvores como camuflagem, Sauron e Saruman não imaginaram ter os domínios de uma de suas torres destruídos por um exército de Ents instigados por dois hobbits.

Em seu livro, The lord of the Rings: the mythology of power, Jane Chance aponta a ineficiência daquele que busca e/ou detém o poder de pensar da mesma forma daquele que não ambiciona o poder e, dessa forma, cair ou ser destituído de seu poder de forma impensável, uma forma por muitas vezes simples. Existem momentos em que o poder é derrotado pelos marginalizados, pois os poderosos não julgam que possam ser derrotados por aqueles “destituídos de poder". ${ }^{10}$ Os detentores de poder se cobrem com um sentimento de invencibilidade e arrogância que os torna cegos e vulneráveis, caindo na perigosa inércia já mencionada. Sauron e Saruman acham que estão protegidos por sua mágica e seus poderes, da mesma forma que Macbeth pensa estar protegido pelas profecias das bruxas sobre acontecimentos "impossíveis" que trariam o fim de seu reinado. Igualmente, a pretensão de Júlio César ignora o aviso para tomar cuidado com os “idos de março”, e ele é morto no dia 15 desse mês.

\footnotetext{
${ }^{9}$ Dentro do mundo criado por Tolkien, os Ents são árvores falantes que vivem de forma pacífica e quase sem nenhum contato com os demais seres da Terra-média.

10 “Because of Sauron's inability to think like a non-Power-seeking Hobbit, He does not guard careful enough the borders of his own Mordor. He lacks the imagination that propels the small Hobbit to take the offensive - attacking Mordor by destroying the one object that could guarantee the diminutive being's power. Furthermore, the divisiveness of the Dark Community has erupted into the treachery of Saruman against his own master, a rebellion fueled by Saruman's Sauron-like greed for the domination and power afforded by possession of the Ring. And thus Saruman similarly does not understand Hobbit difference enough to use that knowledge as power. In his desire for the Ring, Saruman has plotted to capture Merry and Pippin, which has only brought them more efficiently and quickly to Fangorn - in accord with the Company's quest. Gandalf comments on Saruman's inability to perceive difference, both of Hobbit and of tree: 'He does not yet know his peril. There is much that He does not know. I look into his mind and I see his doubt. He has no woodcraft. He believes that the horsemen slew and burned all upon the Field of battle; but He does not know whether the Orcs were bringing any prisoners or not. And he does not know of the quarrel between his servants and the Orcs of Mordor; nor does He know of the Winged Messenger' (2:129). Unfortunately, Saruman must have the Ring in order to battle Mordor, and He Will not have it; He also fights Rohan, and He does not suspect that the Ents will unite to destroy him and his axes as Saruman has attempted to destroy them one by one" (CHANCE. The lord of the rings: the mythology of power, p. 65).
} 
No Ato V, cena VII, Macbeth enfrenta destemidamente a espada do jovem Siward por confiar na profecia das bruxas que disseram que ele não poderia ser morto por nenhum homem que foi nascido de uma mulher. Porém, na cena seguinte, ao enfrentar MacDuff, o arrogante Macbeth escuta a revelação de que MacDuff foi retirado do útero de sua mãe, já que ela não poderia dar à luz de forma natural. Assim, ele não nasceu de uma mulher, mas foi retirado de seu útero. Na cena seguinte, MacDuff entra carregando a cabeça de Macbeth. Ecos da arrogância de Macbeth podem ser percebidos em $O$ retorno do Rei, em que o personagem Witch-king, um dos guerreiros mais temidos de Sauron, carrega consigo o fato de não poder ser morto por nenhum homem. Ele cruza destemidamente o campo de batalha enfrentando os inimigos com a coragem de sua crença até se deparar com Merry, um Hobbit, e Éowyn, uma mulher que havia se disfarçado de homem (uma referência à Joana D’Arc) para lutar junto com o exército de Rohan, que ameaçam impedi-lo:

- Impedir-me? Tú és tolo. Nenhum homem mortal pode me impedir!

Então Merry ouviu o mais estranho de todos os sons daquela hora. Parecia que Dernhelm estava rindo, e sua voz cristalina era como aço. - Mas não sou um homem mortal! Você está olhando para uma mulher. ${ }^{11}$

Em uma ação conjunta, Éowyn e Merry matam o Witch-king, Senhor dos Nazgûl.

A pretensão de invulnerabilidade pode ser encontrada no contexto histórico de Tolkien e Shakespeare; da mesma forma, leitores contemporâneos podem encontrar referências na história atual: o ataque ao World Trade Center pode ser visto como um exemplo. Antes dos atentados, parecia impensável uma afronta de tal magnitude ao "Império Americano”. Isso comprova a continuidade do ciclo dos sistemas baseados nos poderes centralizados.

\section{RESSONÂNCIAS DE A TEMPESTADE EM O SENHOR DOS ANÉIS}

A existência de um ciclo dos sistemas baseados na centralização de poder nos faz pensar sobre qual seria o esqueleto de sustentação de tais sistemas. Ainda mais, ela nos faz pensar em como pode ter se dado seu surgimento. A resposta pode estar no fator que une os membros da espécie humana: o discurso. Através do discurso, (re)produzimos ideologias e damos suporte ao status quo de um sistema. Como podemos comprovar em diversos pontos da análise desenvolvida até agora, as palavras são capazes de modelar os seres e suas crenças. O desenvolvimento de um pensamento crítico, capaz de avaliar o discurso que lhe é apresentado, pode ser a chave para se libertar de um sistema (ou pelo menos, entender e viver

\footnotetext{
${ }^{11}$ TOLKIEN. O senhor dos anéis, p. 890.
} 
de forma mais consciente dentro dele). A capacidade de desenvolver e dar suporte a um discurso, fruto de uma ideologia própria, cria a possibilidade para mudanças/correções em relação aos sistemas do domínio humano.

Em A tempestade, Próspero usa sua mágica para reescrever o destino que lhe foi imposto através da destituição de seu poder no ducado de Milão. Contudo, a reescrita imposta por Próspero, apesar de buscar justiça, possui um aspecto dúbio que faz o perfil do personagem oscilar entre os aspectos positivos e negativos daqueles que detém o poder. A dualidade de Próspero ecoa em $O$ senhor dos anéis através dos personagens Gandalf e Saruman.

Próspero não é apenas um personagem passivo; ele é como um coautor de $A$ tempestade. Suas ações iniciam a peça e seus planos dão continuidade à narrativa. Gandalf recebe tais ressonâncias de Próspero, pois ele é quem mostra a necessidade de Frodo começar sua jornada para destruir o Um Anel e tenta ser uma presença constante na jornada do Hobbit. Grande parte do desenvolvimento da trama de $O$ senhor dos anéis vem das ações de Gandalf, que usa sua mágica e seu conhecimento para auxiliar os povos da Terra-média no combate ao inimigo Sauron. Gandalf e Próspero têm ações altruístas ao abrir mão do poder de certa forma. Gandalf consegue resistir ao poder tentador de usar o Um Anel e Próspero abre mão de sua poderosa mágica antes de voltar para seu posto em Milão.

Saruman emprega seu poder para escravizar e almejar um poder ainda maior, sendo uma ressonância dos aspectos colonialistas de Próspero. Apesar de estar exilado em uma ilha, Próspero tenta controlar todos com quem tem contato: Miranda, Ariel e Caliban. Saruman, da mesma forma, se encontra na torre localizada em Isengard, mas tenta ter o máximo controle dos acontecimentos e de seus subordinados.

Portanto, os dois lados de Próspero refletidos em Saruman e em Gandalf demonstram que o poder tem potenciais, que não precisam ser necessariamente negativos; as relações com o poder podem ser canais para se demonstrar uma virtude e, para tal, devemos ser mais ativos em relação ao que nos é imposto, reconhecendo e imprimindo nossa própria voz.

\section{CONCLUSÃO}

Para Shakespeare, o poder é simbolizado pela coroa, pelo título. Tolkien escolheu o anel como símbolo. Os autores usam tais objetos para expor diversas facetas do poder no domínio humano. Apesar de possuir a forma de um círculo fechado, tanto a coroa quanto o anel são partes do grande espiral das relações de poder através dos tempos. 
A herança que recebemos de Shakespeare é o espírito instigante de sua obra e seu estilo rico ao explorar o humano. Ao percebermos o mosaico do domínio humano como uma espiral que progride, porém conservando sua forma cíclica, entendemos o motivo pelo qual o Bardo nos chega como uma herança rica a ser apreciada. A obra literária se apresenta como uma oportunidade de reflexão sobre os aspectos de nossa própria existência.

Ao abordar de forma mais profunda um tema nas produções literárias, temos a oportunidade de tentar compreender melhor a utilidade da teoria na análise literária. A teoria possibilita uma análise e um entendimento mais rico do objeto literário, principalmente em suas ressonâncias com contextos do domínio humano e intertextualidades com outros objetos literários e de arte. Assim, ao se apresentar como um caminho para uma compreensão mais privilegiada das manifestações literárias, a teoria se torna uma grande aliada da consciência em seus diversos sentidos.

\begin{abstract}
Shakespearean echoes appear in Tolkien's Fantasy literature pointing several aspects of human conflict. This research analyses such echoes with focus on the realm of power relations inherited from the plays Hamlet, Macbeth and The tempest, showing how the power, symbolized as a crown or a ring, may influence human nature.
\end{abstract}

KEYWORDS

Shakespeare, Tolkien, cultural heritage, power

\title{
REFERÊNCIAS
}

ALVIS, John E; WEST, Thomas G. (Ed.). Shakespeare as a political thinker. Wilmington, Delaware: ISI Books, 2000.

CARTER, Lin. O senhor dos anéis: o mundo de Tolkien. Trad. Alves Calado. Rio de Janeiro: Record, 2003.

CHANCE, Jane. The lord of the rings: the mythology of power. Kentucky: University Press of Kentucky, 2001.

CROFT, Janet B. Tolkien and Shakespeare: essays on shared themes and language. Jefferson: McFarland, 2007.

GARBER, Marjorie. Introduction. In: Shakespeare and modern culture. New York: Pantheon, 2008. p. xiii-xxxv. 
GARTH, John. Tolkien and the Great War: the threshold of Middle-earth. New York: Houghton Mifflin Harcourt, 2005.

HÖBEL, Christoph J. R. R. Tolkien's Gandalf and Saruman in the tradition of Shakespeare's Prospero. Ebook disponível em: <http://www.grin.com/en/e-book/143838/j-r-r-tolkien-sgandalf-and-saruman-in-the-tradition-of-shakespeare-s>. Acesso em: 5 jan. 2012.

KOTT, Ian. Shakespeare nosso contemporâneo. Trad. Paulo Neves. São Paulo: Cosac \& Naify, 2003.

LÓPEZ, Rosa S. O senhor dos anéis e Tolkien: o poder mágico da palavra. Trad. Murilo Otávio Rodrigues, Anísio S. Teixeira e Leonidas Contijo de Carvalho. São Paulo: Arte e Ciência, 2004. Disponível em: <http://books.google.com.br/books?id=wV3CZb$1 \mathrm{HfoC} \&$ printsec $=$ frontcover $\& \mathrm{hl}=\mathrm{ptBR} \&$ source $=$ gbs_ge_summary_r\&cad $=0 \# \mathrm{v}=$ onepage $\& q \&$ $\mathrm{f}=$ false $>$.

MATHIJS, Ernest. The lord of the rings: popular culture in global context. London: Wallflower Press, 2006.

ORKIN, Martin; LOOMBA, Ania (Ed.). Post-colonial Shakespeares. London/New York: Routledge: 1998.

POUND, Ezra. ABC da Literatura. Trad. Augusto de Campos e José Paulo Paes. São Paulo: Editora Cultrix, 1970.

SHAKESPEARE, William. The tempest. Boston: Ginn, c1939.

SHAKESPEARE, William. Macbeth. London: Cambridge, 1947.

SHAKESPEARE, William. Julius Caesar. Harmondsworth: Penguin, 1967.

SHAKESPEARE, William. Hamlet. New York: Penguin Books, 2001.

TOLKIEN, J. R. R. O senhor dos anéis. Trad. Lenita Maria Rimoli Esteves e Almiro Pisetta. São Paulo: Martins Fontes, 2002.

TOLKIEN, J. R. R. O Silmarillion. Trad. Waldéa Barcellos. São Paulo: Martins Fontes, 2009. $459 \mathrm{p}$.

VASCONCELOS, ÌRIS H. G. Ligações e afiliações: Shakespeare e o contexto elisabetanojacobino. In: MALUF, Sheila D.; AQUINO, Ricardo B. (Org.). Olhares sobre textos e encenações. Alagoas: Editora UFAL, 2007. p. 117-128. 